Research Article

\title{
YIELD AND YIELD COMPONENTS RESPONSE TO DEFOLIATION OF SPRING WHEAT GENOTYPES WITH DIFFERENT LEVEL OF RESISTANCE TO HELMINTHOSPORIUM LEAF BLIGHT
}

\author{
U.R. Rosyara ${ }^{1}$, R.C. Sharma ${ }^{2}$, S.M. Shrestha ${ }^{2}$ and E. Duveiller ${ }^{2}$ \\ ${ }^{1}$ Institute of Agriculture and Animal Sciences, Rampur Chitwan, Nepal \\ ${ }^{2}$ CIMMYT South Asia, Kathmandu, Nepal \\ Email: urrosyara@hotmail.com
}

\begin{abstract}
Breeding for resistance to Helminthosporium leaf blight (HLB) caused by a complex of spot blotch (Cochliobolus sativus) and tan spot (Pyerenophora tritici-repentis Died) of wheat (Triticum aestivum L.) is difficult due to complex nature of resistance, and high influence of environment. This study was conducted to examine whether genotypes having variation in level of resistance and tolerance differ in compensation to loss of leaves. Five spring wheat genotypes with different levels of resistance and tolerance to HLB were grown under irrigated field conditions in randomized complete block design during 2001-2002 and 20022003 wheat-growing season at Rampur, Chitwan, Nepal. Defoliation treatments consist of removal of flag $(\mathrm{F})$, penultimate (F-1), and both F and F-1 leaves were done one day after anthesis. Results showed that defoliation had significant effects on grain yield, biomass yield, thousand-kernel weight (TKW) but not on harvest index, number of grains per spike, kernel per spikelet, and spikelets per spike. All genotypes included in this study showed some degree of compensation for loss of F, F-1, and both F and F-1 leaves, which was found to be variable between years. Removal of flag leaf was compensated by the resistant genotype NL750 for both grain yield and TKW but not for both F and F-1 leaves. Loss of both F and F-1 leaves was better compensated by BL 1473, a stably tolerant genotype in both years. For other genotypes sensitivity to defoliation was found as variable as tolerance to HLB.
\end{abstract}

Key words: Spot blotch, tan spot, defoliation, compensation, flag leaf removal, penultimate leaf removal

\section{INTRODUCTION}

Helminthosporium leaf blight (HLB), a disease complex caused by Bipolaris sorokiniana Sacc. In Sorok, and Pyrenophora tritici-repentis Died, is a serious concern of wheat in non-traditional "tropical" wheat-growing areas of South East Asia, Latin America, and Africa. On worldwide basis, twenty five million hectares of land is estimated to be under the pressure of HLB (van Ginkel and Rajaram, 1998) causing economic losses. Although different sources of resistance have been identified (van Ginkel and Rajaram, 1998) there is lack of immunity against HLB and only moderate levels of resistance have been found by CIMMYT in some South Asian wheat cultivars (Dubin et al., 1998). Few susceptible cultivars have been reported to display moderate level of resistance with slow progress of the disease and without sustaining appreciable yield loss.

Studies are limiting for elucidating basis of genotypic differences in tolerance to HLB. In other host pathogen system in wheat as Septoria leaf blotch caused by Septoria tritici Rob. Ex. Desm. selected high thousand kernel weight (TKW) lines were found to respond similarly to Septoria stress and draught, retaining high yield components (Ziv et al., 1981). The results indicate genetically controlled endurance of yield components of tolerant cultivars may represent general compensatory response mechanisms that result in stability under stress conditions. Compensation for yield and yield attributes to defoliation has been normal phenomena in studies including artificial defoliation (Buttrose and May, 1959; Throne, 1963). Removal or shading of flag leaf has been found to be associated with increased assimilates from second leaf to ear at expense of the root system (Wardlaw et al., 1965; Carr and Wardlaw, 1965). Compensation to removal of flag leaf alone or lower leaves was evident as such treatments had no significant effect on dry weight after anthesis, reduction of number of grains $\mathrm{m}^{-2}$ or grain yield, however slight reduction in TKW was observed (Aggrarwal et al., 1990). Similarly defoliation 
has been reported to reduce both dry weight and nitrogen content of grains with variation between cultivars (Wardlaw et al., 1965). Removal of top leaves reduced grain yield by $13.5 \%$, spike weight by $9.2 \%$, TKW by $7.6 \%$ without significant reduction of grains $\mathrm{m}^{-2}$ (Asghar and Ingram, 1993). A susceptible bread wheat cultivar to Septoria tritici Blotch (STB), Miriam, maintained kernel weight under sever epidemics of STB, mechanical defoliation, and chemical defoliation (Zilberstein et al., 1985, Ziv and Eyal, 1978). Compensation by carbohydrate supply from unaffected tissues were suggested by Zilberstein et al. (1985) as a possible mechanism responsible for grain filling in tolerant cultivars under STB stress. Later for the same host pathogen system Zuckerman et al. (1997) observed rate of carbon fixation per unit of chlorophyll and per residual green leaf area of an infected tolerant cultivar, Miriam, was higher than healthy plants. The result purposed that the enhanced photosynthesis in residual green tissue of infected tolerant cultivar Miriam compensates the loss of photosynthesizing tissue due to Mycosphaerella graminicola. For HLB in spring wheat information are limiting on whether there is genotypic difference existing for compensation behavior attributable to difference in level of resistance and tolerance.

Previous studies suggest that in healthy plants, grain growth do not appear to be limited by supply of assimilates during sink filling than sink development (Fischer and Aguilar, 1976). Post anthesis source limitation has been suggested as an indication of sensitivity to post anthesis stresses, such as water or high temperature (Fischer and HilleResLambers, 1978). Significant variation in post-anthesis source limitations has been found (Bruckner and Frohberg, 1991), although it was not applicable in routine screening of diverse germplasms due to poor precision. HLB stress and other several stresses under non-traditional wheat growing areas come together. This leads to test our hypothesis whether genotypes with low source limitations are more tolerant to HLB stress. The objective of the study was to identify whether genotypes having different level of resistance and tolerance to HLB differ in compensation to defoliation.

\section{MATERIALS AND METHODS}

Five spring wheat genotypes possessing diverse genetic background with different levels of resistance and tolerance to HLB, namely Sonalika, Kanchan, BL 1473, Nepal 297 and NL750 were grown at Rampur, Chitwan, Nepal (27 37’ N, 84 24' E and 228 meters above sea level) during winter season of 2001-2002 and 2002-2003 under irrigated field conditions. The experiment was conducted in a four-replicated Randomized Complete Block design with spray arranged in the first strip, and full factorial combination of genotypes and defoliation, in the second strip. The plot size was $2 \times 1 \mathrm{~m}$ consisting of $2 \mathrm{~m}$ long four rows seeded at $0.25-\mathrm{m}$ row spacing with $120 \mathrm{~kg}$ seed ha ${ }^{-1}$. The experiment was seeded on normal planting dates: $22^{\text {nd }}$ November, 2001 and $7^{\text {th }}$ December, 2002. Leaf removal treatments include removal of flag, penultimate leaf, both flag and penultimate leaves, and no defoliation control. Leaf blades were removed one day after anthesis at legule with scissors leaving leaf sheath intact from all tillers in the two middle-rows consisting of $1 \mathrm{~m}^{2}$ of net plot area in plot receiving defoliation treatment. Fertilizers were applied @120, 60, and 40-kg/ha of N, $\mathrm{P}_{2} \mathrm{O}_{5}$, and $\mathrm{K}_{2} \mathrm{O}$, respectively. Split application of nitrogen was done at $100-\mathrm{kg} / \mathrm{ha}$ as basal broadcasting and rest $20-\mathrm{kg} / \mathrm{ha}$ as top-dressed at maximum tillering stage. In disease protected plots 'Opus' (Epoxiconazol) $0.05 \%$ a. i. was sprayed four times at seven-day intervals starting 50 days after seeding between growth stage 69 to 89 decimal code (Zadoks et al., 1974). Four disease scores for HLB were recorded as the percent of diseased leaf area on flag leaves for individuals selected and tagged after anthesis. Area under disease progress curve (AUDPC) was calculated using the following formula as previously used by Das et al. (1992).

$$
\begin{aligned}
& \text { AUDPC }=\sum_{i=1}^{n-1}\left[\left(\frac{X_{(i+1)}+X_{i}}{2}\right)\right]\left(T_{(i+1)}-T_{i}\right) \\
& \text { where, } \\
& \quad \mathrm{X}_{\mathrm{i}}=\text { disease severity on the } \mathrm{i}^{\text {th }} \text { date } \\
& \mathrm{T}_{\mathrm{i}}=\text { date on which the disease was scored } \\
& \mathrm{n}=\text { number of dates on which disease was recorded }
\end{aligned}
$$

The central two rows of the whole plot was cut at ground level, sun dried to constant weight, weighed, threshed and grain weight was recorded for determination of harvest index and biomass yield. The grain yield and TKW were measured at $12 \%$ moisture basis. Effective tiller number was counted in each plot just before harvesting. Ten random samples of spikes were taken per plot to measure grains per spike, spikelets per spike, 
and kernels per spikelet. Grain yield loss for each genotype was estimated as the ratio of yield differences in sprayed and non-sprayed plots with yield of spray. Testing of normality of data using Anderson- Darling test and analysis of variance was carried out with general linear procedure of MINITAB (1996).

\section{RESULTS AND DISCUSSION}

Defoliation at anthesis showed a significant effect $(\mathrm{P}<0.01)$ on grain yield, biomass yield, TKW but not on harvest index, number of grains per spike, number of kernels per spikelet, and number spikelets per spike suggesting defoliation did not affected sink size. A non-significant effect of defoliation on harvest index shows that grain yield reduction was proportionate to biomass reduction. Main effect for harvest index was non significant with significant year-defoliation interaction $(\mathrm{P}<0.05)$ and genotype-year interaction $(\mathrm{P}<0.01)$. Removal of flag leaf blade at anthesis did not significantly affect number of kernels per spikelet (table 1 ) in contrast to observation of Blade and Backer (1991). Comparison of the components of yield (especially number of grains $\mathrm{m}^{-2}$ and TKW) under defoliation can indicate source sink effect. Sink size was not affected by defoliation as also reported by Aggarwal et al. (1990). The result supports the argument that number of grains $\mathrm{m}^{-2}$ is determined by the assimilate source supply during 30 days or so before anthesis. Genotype x defoliation interaction was significant for grain yield and biomass yield for the first year only suggesting that effect of defoliation was not proportionate in all genotypes possibly due to difference in contribution and compensation behavior and is also subjected to environmental changes (Table 1).

Table 1. Analysis of variance for yield and yield components in the study of effect of defoliation on different spring wheat genotypes evaluated in 'Opus' sprayed and non-sprayed plots in 2001 and 2002 wheat growing season at Rampur, Nepal

\begin{tabular}{|c|c|c|c|c|c|c|c|c|}
\hline \multirow[t]{2}{*}{ Source } & df & $\begin{array}{l}\text { Grain } \\
\text { yield }\end{array}$ & TKW & Biomass yield & HI & $\begin{array}{l}\text { Grains per } \\
\text { spike }\end{array}$ & $\begin{array}{l}\text { Spikelets per } \\
\text { spike }\end{array}$ & $\begin{array}{l}\text { Kernels per } \\
\text { spikelet }\end{array}$ \\
\hline & & $\mathrm{g} \mathrm{m}^{-2}$ & $\mathrm{~g}$ & $\mathrm{~g} \mathrm{~m}^{-2}$ & - & & & \\
\hline Year $(Y r)$ & 1 & 13113 & 51.6 & 28016 & 0.0098 & 660.31 & 19.681 & 1.5401 \\
\hline Error (a) & 6 & 9175 & 280.6 & 52930 & 0.0067 & 363.47 & 16.293 & 1.1869 \\
\hline Spray (Spr) & 1 & $120659^{* *}$ & $1553.8^{* *}$ & $422402^{* *}$ & $0.0248 *$ & 22.54 & 5.701 & 0.04515 \\
\hline Yrx Spr & 1 & $17183^{* * *}$ & $1253.0^{* *}$ & $881811^{* * *}$ & 0.0041 & 23.14 & 7.548 & 0.4366 \\
\hline Error (b) & 6 & 3361 & 68.8 & 9586 & 0.0028 & 13.88 & 14.386 & 0.3426 \\
\hline Defoliation (Def) & 3 & $8254^{*}$ & $217.2^{* *}$ & 57979 ** & 0.0009 & 15.04 & 2.008 & 0.0026 \\
\hline Genotypes (Geno) & 4 & $11514^{* *}$ & $207.3^{* *}$ & $60127^{* *}$ & 0.0026 & $244.84 * *$ & $19.411 * *$ & $0.8101^{* *}$ \\
\hline Def X Geno & 12 & 1484 & 16.5 & 6251 & 0.0013 & 40.14 & 1.74 & 0.1208 \\
\hline Yrx Def & 3 & $30851 * *$ & $165.9 * *$ & $131448^{* *}$ & $0.0055^{*}$ & 20.33 & 4.483 & 0.0475 \\
\hline Yrx Geno & 4 & $19947^{* *}$ & $228.1^{* *}$ & $37480^{*}$ & $0.0140^{* *}$ & $169.92^{* *}$ & $16.236^{* *}$ & $0.4727^{* *}$ \\
\hline Yrx Def x Geno & 12 & 2126 & 9.4 & 13534 & 0.0013 & 19.05 & $3.897 *$ & 0.0887 \\
\hline Error $(c)$ & 114 & 2136 & 15.1 & 12650 & 0.0016 & 22.53 & 1.914 & 0.1124 \\
\hline Spr x Def & 3 & 2393 & 22.7 & 3193 & 0.0029 & 12.38 & 1.325 & 0.0983 \\
\hline Spr x Geno & 4 & $8913^{* *}$ & $37.5^{*}$ & $30239 *$ & $0.0110^{* * *}$ & 41.63 & 1.84 & 0.1947 \\
\hline Spr x Def x Geno & 12 & 1840 & 24.2 & 8692 & 0.0021 & 42.26 & 1.887 & 0.1393 \\
\hline Yrx Spr x Def & 3 & 1948 & 18.1 & 23652 & $0.0060^{* *}$ & $86.92^{*}$ & 1.531 & $0.4937 * *$ \\
\hline Yr x Spr x Geno & 4 & 2797 & $74.8^{* * *}$ & 8176 & 0.0030 & 64.03 & 1.746 & 0.197 \\
\hline Yr x Spr x Def x Geno & 12 & 704 & 15.6 & 5472 & 0.0011 & 29.2 & 2.025 & 0.1179 \\
\hline Pooled Error & 114 & 2120 & 12.9 & 9455 & 0.0013 & 27.81 & 2.157 & 0.1145 \\
\hline
\end{tabular}

*, **, *** Significant at $0.05,0.01$, and 0.001 probability levels respectively, ns- non significant $(\mathrm{P}>0.05)$, df- degrees of freedom, HI - harvest index, TKW- thousand kernel weight 
Defoliation treatments
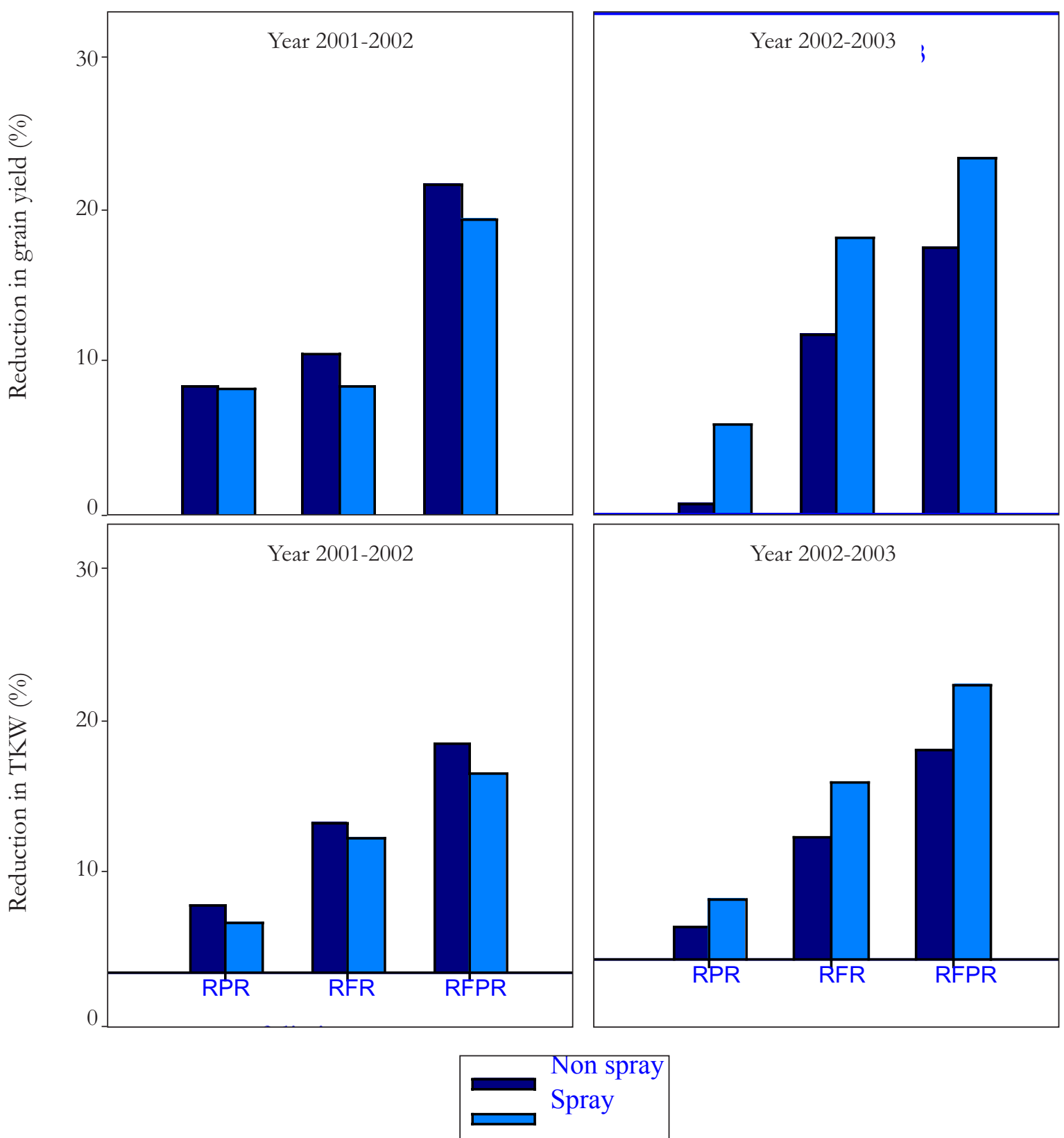

Figure 1. Effect of defoliation on thousand-kernel weight and grain yield averaged over genotypes in spring wheat genotypes grown under diseaseprotected condition at Rampur, Chitwan, Nepal during 2001-2002 and 2002-2003 (Reduction due to removal of penultimate leaf (RPR), flag leaf (FPR), and both flag and penultimate leaves (RFPR)

Removal of penultimate leaves was better compensated by all of the genotypes both in spray and nonspray environments, since loss in grain yield and TKW as compared to non-defoliated control was less than $10 \%$ except in few cases (Fig 1, Table 2). On an average removal of penultimate leaves reduced TKW by 4\% and $6 \%$ in grain yield. The result was consistent with reports showing very little role of penultimate leaf and ear receives assimilates exclusively from flag leaf (Quinlan and Sagar, 1962; Wardlaw, 1965; Lupton, 1966). 
Table 2. Grain yield and thousand-kernel weight of six wheat genotypes under defoliation treatments in disease protected and disease unprotected environments grown at wheat season of 2001 and 2003 at Rampur, Chitwan, Nepal

\begin{tabular}{|c|c|c|c|c|c|}
\hline \multirow{3}{*}{ Genotypes } & \multirow{3}{*}{ Defoliation } & \multicolumn{2}{|c|}{ Grain yield } & \multicolumn{2}{|c|}{ Thousand kernel weight } \\
\hline & & Spray $\$$ & Non spray & Spray & Non spray \\
\hline & & \multicolumn{2}{|c|}{-----------g m-2---------- } & \multicolumn{2}{|c|}{------------------g------------------ } \\
\hline \multirow{4}{*}{ Sonalika } & None & 322 & 219 & 43.8 & 33.9 \\
\hline & Penultimate & 303 & 222 & 44.8 & 33.2 \\
\hline & Flag & 270 & 184 & 39.0 & 29.3 \\
\hline & Flag and Penultimate & 229 & 159 & 37.3 & 29.4 \\
\hline \multirow[t]{4}{*}{ Kanchan } & None & 349 & 294 & 46.2 & 39.3 \\
\hline & Penultimate & 322 & 251 & 42.0 & 36.2 \\
\hline & Flag & 312 & 250 & 42.5 & 33.8 \\
\hline & Flag and Penultimate & 284 & 215 & 40.8 & 32.3 \\
\hline \multirow[t]{4}{*}{ BL 1473} & None & 320 & 274 & 48.8 & 45.1 \\
\hline & Penultimate & 274 & 254 & 47.7 & 43.6 \\
\hline & Flag & 266 & 217 & 43.5 & 40.7 \\
\hline & Flag and Penultimate & 279 & 234 & 42.3 & 38.8 \\
\hline \multirow[t]{4}{*}{ Nepal 297} & None & 334 & 282 & 47.9 & 42.4 \\
\hline & Penultimate & 347 & 239 & 46.0 & 40.1 \\
\hline & Flag & 290 & 248 & 44.2 & 38.1 \\
\hline & Flag and Penultimate & 266 & 217 & 40.6 & 35.4 \\
\hline \multirow[t]{4}{*}{ NL750 } & None & 359 & 289 & 41.7 & 35.1 \\
\hline & Penultimate & 354 & 285 & 39.9 & 34.9 \\
\hline & Flag & 347 & 277 & 38.0 & 33.3 \\
\hline & Flag and Penultimate & 282 & 234 & 33.7 & 28.5 \\
\hline $\operatorname{LSD}(0.05) \#$ & & & & & 4.1 \\
\hline
\end{tabular}

S Sprayed with the fungicide Epoxiconazole; \#LSD value (0.05) using pooled error to compare spray $\mathrm{x}$ defoliation $\mathrm{x}$ spray interactions

Removal of flag leaf reduced grain yield by $\approx 12 \%$ and TKW by $\approx 10 \%$ with no yield loss to a maximum reduction of $23 \%$. Removal of flag leaf in NL750 has less grain yield and TKW reduction. Such small changes in yield due to removal of all flag leaves can be explained in terms of lower leaves, stems, and sheaths taking over the role of the flag leaves and the consequent increase in light intensities (little extra light reaching to the lower canopy). In contrast to higher dependence of ears on the flag leaf, there were little reductions in grain yield and TKW due to removal suggesting compensation possibly by penultimate leaves (Carr and Wardlaw, 1965) as after anthesis only top two leaves were found to be effective in photosynthesis (Puckridge, 1969). This was further supported by the reduction in TKW due to removal of upper two leaves was comparable to complete defoliation studies (Aggarawal et al., 1990) and reduction in grain yield (Blade and Backer, 1991). In general this shows that wheat genotypes have strong compensation for loss of even upper two leaves.

Removal of both $\mathrm{F}$ and $\mathrm{F}-1$ leaves reduced grain yield by $\approx 21 \%$ and TKW by $\approx 15 \%$. A wide variation existed for reduction in grain yield and TKW due to loss of both leaves among genotypes ranging between 10 to $34 \%$ for grain yield and 8 to $28 \%$ for TKW. This shows that wheat genotypes have strong compensation for loss of even upper two leaves. Lower value of yield reduction than expected for removal of F leaf and F-1 leaf for all genotypes show the role of other sources in stabilizing yield particularly spike photosynthesis, stem reserves, photosynthetic behavior of leaf sheath and peduncles. There could also be an increase in compensatory efficiency of light utilization or some remobilization of soluble sugars.

The research was initiated with the hypothesis that tolerant genotypes have more stress buffering capacity due to higher contribution of other sources than the upper two leaves. Alternatively there may be compensatory changes for sources due to loss of effective leaf area from leaf. Remobilization of preanthesis stored assimilates from leaf and stem tissues, which has been associated with postanthesis stress tolerance in wheat and barley (Austin et al., 1980; Bidinger et al., 1977; Blum et al., 1983; Rawson and Evans, 1971). There could also be compensatory increase in photosynthesis of spikes, leaf sheaths, and peduncles contributing to increased yield in tolerant genotypes. Also, storage and their mobilization to sink under disease stress conditions, or compensation 
in photosynthetic capacity, relative to non-diseased tissue were suggested as a possible mechanisms associated with tolerance (Kramer et al., 1980). Based on these it was hypothesized that genotypic differences for compensation and contribution from sources other than upper two leaves exists for grain yield and TKW.

Significant difference exists for genotypes for HLB severity (AUDPC) with significant $(\mathrm{P}<0.01)$ genotype $\mathrm{x}$ year interaction (Table 4). NL750 was found fairly resistant in both years (Table 3). The data show that there is wide variation in yield loss estimates and AUDPC for the set of genotypes included in the study. Previously reported genotypes having moderate level of resistance Nepal 297 (Dubin et al., 1998) and BL 1473 have higher HLB that was comparable to the susceptible Sonalika for both years under both high (2001) and moderate disease pressure (2002) leading to breakdown of such property. Under higher disease pressure of HLB such a breakdown was previously reported (Duvellier et al., 1998). On an average there were higher values of yield loss estimates for the second year. However it seems that BL 1473 is relatively more consistent for yield loss estimates fluctuations (Table 3). Even with higher disease pressure in the first year and moderate pressure in the second year, yield loss estimates did not exceeds to 15\%. BL 1473 respond to loss of both flag and penultimate leaves in the similar way in both years comparable with effects of removal of both leaves. It seems that there is some mechanism that contribute to stabilizing yield under stress condition. Tolerance property of Nepal 297 indicated by disease severity and yield loss was not stable in the study and was as variable as reduction in grain yield or TKW. The effect of loss of TKW due to HLB was much higher in most of cases than due to loss of upper two leaves. It seems that there exists some degree compensating mechanisms in all genotypes in healthy conditions. Interestingly the most susceptible genotype, Sonalika, and fairly resistant genotype, NL750, were found to be much sensitive to loss of upper leaves. In spite of low AUDPC, there was appreciable yield loss estimates due to HLB for gain yield and TKW in both years. In later stages of growth cycle the HLB also affects the resistant genotypes even symptom less isolation of the pathogens have been reported (unpublished data). There was less difference in the incidence of HLB pathogens in later stages of growth cycle. Such sensitiveness leads to suspect show that there could be poor mechanism for stabilizing yield in the genotype. This need to be tested further that whether there is a genetic basis for yield stabilizing mechanisms and could be transferred through breeding procedures to stabilize the yield under stressed environments.

Factors playing role in stabilizing yield in tolerant genotypes like BL 1473 could not be fully elucidated by the study. This requires quantification of each component such as measurement of photosynthesis of spike, quantification of contribution from stems reserves and photosynthesis of leaf sheath and peduncles. Enhanced photosynthesis in residual green tissue of infected plants could compensate for the loss of photosynthesizing tissue due to the HLB pathogens. In a similar study in STB tolerant cultivar carbon fixation per unit of chlorophyll and per residual green leaf area of infected tolerant cultivar was higher than healthy plants (Zuckerman et al., 1997). Further more there exists a possibility for high initial grain filling rates, and strong photosynthesis system with high chlorophyll content so that source is not limited in early season in spite of higher severity of HLB. However stem reserves was not found playing role in compensating yield loss due to STB in tolerant cultivar (Zuckerman et al., 1997).

As such for this set of genotypes artificial source manipulation was not found to be useful criteria for screening of more stress tolerant genotypes including HLB stress due to restriction in not using larger plot size, a large manpower requirement, and requirement for application of treatments in a short period of time in breeding programs. Such a technique even though elucidated the tolerance of BL 1473 in which effect of removal of both F and F-1 was similar to yield loss estimates due to HLB. For majority of the genotypes the effect of defoliation was as variable as yield loss estimates between years (Table 3). A genotype with low sensitivity to defoliation with less environmental variations like BL 1473 may be preferred with stable performance under stressed environments. 
Table 3. Resistance and tolerance to Helminthosporium leaf blight and sensitivity to loss of upper two leaves in disease protected environments in spring wheat genotypes evaluated during 2001-2002 and 2002-2003 grown in field conditions at Rampur, Chitwan, Nepal

\begin{tabular}{|c|c|c|c|c|c|c|c|c|c|c|}
\hline \multirow{3}{*}{ Genotypes } & \multicolumn{2}{|c|}{ AUDPC } & \multicolumn{4}{|c|}{$\begin{array}{l}\text { Reduction due to disease in non- } \\
\text { defoliated control plots (\%) }\end{array}$} & \multicolumn{4}{|c|}{$\begin{array}{l}\text { Reduction due to removal of flag } \\
\text { and penultimate leaves in disease- } \\
\text { protected environment (\%) }\end{array}$} \\
\hline & \multirow[t]{2}{*}{2001} & \multirow[t]{2}{*}{2002} & \multicolumn{2}{|c|}{2001} & \multicolumn{2}{|c|}{2002} & \multicolumn{2}{|c|}{2001} & \multicolumn{2}{|c|}{2002} \\
\hline & & & GRY & TKW & GRY & TKW & GRY & TKW & GRY & TKW \\
\hline & & & & & & --- & & & & \\
\hline Sonalika & $1343^{\mathrm{A} \uparrow}$ & $778^{C}$ & 27.3 & 14.2 & 36.5 & 30.0 & 31.1 & 13.2 & 27.1 & 16.3 \\
\hline Kanchan & $882^{C}$ & $432^{\mathrm{E}}$ & 8.0 & 12.8 & 23.0 & 17.3 & 18.3 & 10.2 & 18.8 & 13.2 \\
\hline BL 1473 & $1244^{\mathrm{A}}$ & $508^{\mathrm{E}}$ & 15.0 & 4.9 & 13.3 & 9.9 & 14.7 & 13.2 & 10.6 & 13.5 \\
\hline Nepal 297 & $1107^{\mathrm{B}}$ & $628^{\mathrm{D}}$ & 8.8 & 11.6 & 23.2 & 11.6 & 28.4 & 18.1 & 10.2 & 12.6 \\
\hline NL750 & $223^{\mathrm{F}}$ & $17^{\mathrm{G}}$ & 15.6 & 15.8 & 22.7 & 16.1 & 19.0 & 23.3 & 23.3 & 15.9 \\
\hline LSD (0.05) & 104.6 & & & & & & & & & \\
\hline
\end{tabular}

AUDPC- Area Under Disease Progress Curve, TKW- Thousand kernel weight, GRY- Grain Yield, I Means followed by the same letter are not significantly different from one another

Table 4. Analysis of variance for Area Under Helminthosporium Leaf Blight Progress Curve for five spring wheat genotypes grown during wheat season at Rampur, Chitwan, Nepal

\begin{tabular}{|lcc|}
\hline Source & Degrees of freedom & Mean sum of square \\
\hline Year & 1 & $2375709^{* * *}$ \\
Error (a) & 6 & 21771 \\
Genotype & 4 & $1051406^{* * *}$ \\
Year x Genotype & 4 & $74159^{* * *}$ \\
Pooled Error & 24 & 5113 \\
\hline
\end{tabular}

\section{ACKNOWLEDGMENTS}

The financial support for the research was received from USAID/ CDR grant number TA-MOU-97C17-005. Partial support was also obtained through DGIC funding from Beljium Government to CIMMYT, South Asia.

\section{REFERENCES CITED}

Aggarawal, P.K., R.A. Fischer, and S.P. Liboon. 1990. Source-sink relations and effects of post anthesis canopy defoliation in wheat at low latitudes. J. Agric. Sci. Cambridge 114: 93-99.

Asghar, M., and B.F. Ingram. 1993. Effect of defoliation on dry land wheat production in central Queensland. Aust. J. Exp. Agri. 33:349-351.

Austin, R.B., J.A. Edrich, M.A. Ford, and R.D. Blackwell. 1980. Contribution to grain yield from pre-anthesis assimilation in tall and dwarf barley phenotypes during two contrasting seasons. Ann. Bot. (London). 45: 309-319.

Bidinger, F., R. B. Musgrave, and R. A. Fischer. 1977. Contribution of stored pre-anthesis assimilates to grain yield in wheat and barley. Nature (London) 270: 431-433.

Blade, S. F., and R. J. Baker. 1991. Kernel weight response to source-sink changes in spring wheat. Crop Sci. 31: 1117-1120.

Blum, A., H. Poiarkova, G. Golan, and J. Mayer. 1983. Chemical desiccation of wheat plants as a stimulator of post-anthesis stress: I. Effects on translocation and kernel growth. Field Crops Res. 6: 51-58.

Bruckner, P. L., and R. C. Frohberg. 1991. Source-sink manipulation as a postanthesis stress tolerance screening technique in wheat. Crop Sci. 31:326-328.

Buttrose, M.S., and L.H. May. 1959. Physiology of cereal grain. I. The source of carbon for developing barley kernel. Aust. J. boil. Sci. 12: 40-52.

Carr, D.J., and I.F. Wardlaw. 1965. The supply of photosynthetic assimilates to the grain from the flag leaf and ear of wheat. Aust. J. Biol. Sci. 18: 711-719.

Das, M.K., S. Rajaram, C.C. Mundt, and W.E. Kronstad. 1992. Inheritance of slow rusting resistance to leaf spot in wheat. Crop Sci. 32: 1452-1456. 
Dubin, H.J., B. Arun, S.N. Begum, M. Bhatta, R. Dhari, L.B. Goel, A.K. Joshi, B.M. Khanna, P.K. Malaker, D.R. Pokhrel, M.M. Rahman, N.K. Saha, M.A. Shaheed, R.C. Sharma, A.K. Singh, R.M. Singh, R.V. Singh, M. Vergas, and P.C. Verma. 1998. Result of South Asian regional Helminthosporium leaf blight and yield experiment 1993-1994. In: Duveiller, E., H.J. Dubin, J. Reeves, and A. McNab, (eds.) Helminthosporium blights of wheat: Spot blotch and tan spot. CIMMYT, Mexico. pp. 182-187.

Duveiller, E., I. Gracia, J. Franco, J. Toledo, J. Crossa, and F. Lopez. 1998. Evaluating spot blotch resistance of wheat: Improving disease assessment under controlled conditions and in the field. In: Duveiller, E., H.J. Dubin, J. Reeves, and A. McNab, (eds.) Helminthosporium blights of wheat: Spot blotch and tan spot. CIMMYT, Mexico. pp. 171-181.

Fischer, R.A., and D. HilleRislambers. 1978. Effect of environment and cultivar on source limitation to grain weight in wheat. Aust. J. Agric. Res. 29: 443-458.

Fischer, R.A., and I. Aguilar. 1976. Yield potential in a dwarf spring wheat and the effect of carbon dioxide fertilization. Agron. J. 68: 749-752.

Kramer, T., B. H. Gildemancher, M. van der Ster, and J. E. Parlevliet. 1980. Tolerance of spring barley cultivars to leaf rust, Puccinia hordei. Euphytica 29: 209-216.

Lupton, F.G.H. 1966. Translocation of photosynthetic assimilates in wheat. Ann. appl. Biol. 57: 355-364.

MINITAB. 1996. MINITAB for windows, US: Minitab Inc.

Puckridge, D.W. 1969. Photosynthesis of wheat under field conditions II. Effects of defoliation on the carbon dioxide uptake of the community. Aust. J. agric. Res. 20: 623-634.

Quinlan, J.D., and G.R. Sagar. 1962. An auto radiographic study of movement of 14C labeled assimilates into developing wheat plant. Weed Res. 2: 264-273.

Rawson, H.M., and L.T. Evans. 1971. The contribution of stem reserves to grain development in a range of wheat cultivars of different height. Aust. J. agric. Res. 22:851-863.

Thorne, G.N. 1963. Varietal differences in photosynthesis in ears and leaves of barley. Ann. Bot. N. S. 27:156174.

van Ginkel, M., and S. Rajaram. 1998. Breeding for resistance to spot blotch in wheat: Global perspective. In: Duveiller, E., H.J. Dubin, J. Reeves, and A. McNab, (eds.), Helminthosporium blights of wheat: Spot blotch and tan spot. CIMMYT, Mexico. pp. 157-161.

Wardlaw, I.F. 1965. The velocity and pattern of assimilate translocation in wheat plants during grain development. Aust. J. Soil. Sci. 18: 269-281.

Wardlaw, I.F., D.J. Carr, and M. Jean Aderson. 1965. The relative supply of carbohydrate and nitrogen to wheat grains and an assessment of shading and defoliation techniques used for these determinations. Aust. J. Agric. Res. 16: 893-901.

Zadoks, J.C., T.T. Chang, and C.F. Konzak. 1974. A decimal code for the growth stages of cereals. Weed Res. 14:415-421.

Zilberstein, M., A. Blum, and Z. Eyal. 1985. Chemical desiccation of wheat plants as a stimulator of photosyntheisis speckled leaf blotch stress. Phytopath. 75: 225-230.

Ziv, O., and Z. Eyal. 1978. Assessment of yield component losses caused in plants of spring wheat cultivars by selected isolates of Septoria tritici. Phytopath. 68: 791-796.

Ziv, O., J.M. Sacks, and Z. Eyal. 1981. Inheritance of tolerance to Septoria leaf blotch of wheat. The Amer. Phytopath. Soc. 72:119-123.

Zuckerman, E., A. Eshel, and Z. Eyal. 1997. Physiological aspects related to tolerance of spring wheat cultivars to Septoria tritici blotch. Phytopath. 87: 60-65. 